\title{
Opinion \\ Transformational psychological workbook for greater self-understanding and self-development
}

\author{
Volume 3 Issue I - 2015 \\ Max Hammer, Barry Hammer, Alan C Butler \\ The University of Maine, USA
}

\section{Editorial note by barry hammer}

The text of this article comes from an undated tape recorder audio tape recorded by my late father, Max Hammer. The text that appears in brackets [ ] in this article consists of interpretive editorial insertions by me, whereas the remainder of the text, outside of the brackets (i.e., sections of the text that are not within the brackets), comprises my transcription of the actual remarks by Max Hammer that were recorded on the original audio tape.

\section{Opinion}

One of the most useful instruments for long term self-development is a workbook, diary, or journal. We use the term "psychological workbook" because many people tend to associate the word "diary" with recording often trivial and burdensome accounts of one's daily activities, without engaging in deeper reflection and insight. The type of workbook suggested here has as its purpose the recording of your inner life, as well as its causes and developments. Outer factual events may be recorded inasmuch as they are significantly related to inner events (such as, feelings, thoughts, desires, observations), but the focus should be on the unfolding awareness of oneself and the world, and on the significant new meanings, values, and inter-relationships between various aspects of one's experience and endeavors that one is able to discover and develop.

There are many purposes for keeping a workbook or journal of this sort. One of the most important is to help ourselves formulate our thoughts, feelings, and observations with greater clarity and with more substantial reflection. And in the act of putting something on paper, we tend to commit ourselves to more precisely clarifying, expanding, and reflecting upon our thoughts and feelings, to a greater extent. We are taking a step beyond simply thinking or saying something when we make the effort to write it down. Also, in the process of thought clarification through writing, we are obliged to choose between various alternative viewpoints, so we are thus less likely to deceive or confuse ourselves by holding contradictory, ambiguous, unclear, or superficial, underdeveloped, unexamined, views without being aware of it. If there is a problem to be solved or an area of real confusion, we are better able to define it, and thus take the first step towards its meaningful resolution.

The act of writing is also a great stimulus to the creative process. When we are trying to grapple with a problem, it is a common experience that in writing down a few thoughts on the question, other related thoughts begin to stream in, through a process of association, and these ideas in turn open up new avenues of thought, new possibilities that we may not have considered before. If we can learn to let our minds range freely in this manner, we will be truly amazed to discover the depth of the insights already within us, just waiting to be evoked and liberated.

Keeping a workbook as a technique of self-understanding and self-development also functions in other significant beneficial ways.
Correspondence: Barry hammer, The University of Maine, 15 Downeast Terrace, Apt. 2 Orono, Maine (ME) 04473, USA, Tel 207-866-3223,Email mhbj58@gmail.com

Received: June 10,2015 | Published: June 17, 2015

It gives us an opportunity to express, in a harmless way, any powerful and disruptive emotions we may have bottled up inside us. If we can learn to "let off steam" through writing, we will have a useful means of discharging tensions, and of becoming aware of what underlies them, as causal factors and/or related experiential and/or cognitive connotations. Writing is also a useful exercise for developing our faculties of concentration and attention. It may help a person who is somewhat shy, and reluctant to express himself in a face-to-face setting, to explore certain aspects of himself more freely. For all of these reasons, keeping a psychological development workbook, or journal, comprised of various contemplative or reflective exercises, can be an important aspect of the Psycho-synthesis process, i.e., the process of psychological self-integration, or self-unification. This is a method which one can employ on her own initiative, as she takes the process of her transformational growth and self-realization, or insightful self-discovery, increasingly into her own hands.

In addition to composing written materials, one can also make drawings and other visual aids a part of the contemplative workbook or journal. These may be of various kinds. In one category are images, which may come to you in the form of dreams, fantasies, or visualizations. In another category are diagrams, more abstract symbols, or visual aids which we can use to express our ideas in graphic form. This is useful in developing clear concepts and in communicating these concepts to others. Another category is what one might call "spontaneous drawing." This should be done when we are in a relaxed state of mind, and when our attention is fixed on something else, such as when we are doodling. Such drawings reflect the activity of the unconscious mind and may be of value in gaining greater self-understanding. Thus, drawing as well as writing can be part of a complete workbook. A psychological workbook or journal can also record and react to other self-expressive activities such as, singing, playing a musical instrument, dance, other performing arts,crafting, attending athletic sports events as a spectator or active participant, outdoor activities in beautiful nature, and/or dialoguing with trusted friends or family about significant issues and questions related to our lifeand/or theirs. Those kinds of creative-expressive activities can also be utilized as a means of evoking intensely energized feelings and insightful thoughts that may be significant or important to us, but which may have previously been dormant or not fully consciously recognized prior to being evoked through such creative self-expressive activities. 
For more extensive discussions of the authors' insights, please see their two published books. The primary author of the books is Dr. Max Hammer, with secondary contributing authors Dr. Barry Hammer and Dr. Alan C. Butler. The titles of our books are as follows: 1) Psychological Healing Through Creative Self-Understanding and Self-Transformation. (ISBN 978-1-62857-075-5). 2) Deepening Your Personal Relationships: Developing Emotional Intimacy and Good Communication. (ISBN: 978-1-6198-590-4).

\section{Acknowledgments}

None.

\section{Conflicts of interest}

Author declares there are no conflicts of interest.

\section{Funding}

None. 